\title{
Outcomes and Prognostic Factors for Adenocarcinoma/Adenosquamous Carcinomas Treated with Radical Hysterectomy and Adjuvant Therapy
}

\author{
Masayuki Yamaguchi*, Yoko Yamagishi, Nobumichi Nishikawa, Masayuki Sekine, \\ Takehiro Serikawa, Katsunori Kashima, Takayuki Enomoto \\ Department of Obstetrics and Gynecology, Graduate School of Medical and Dental Sciences, Niigata University, \\ Niigata City, Japan \\ Email: ․ㅡㄹamag@med.niigata-u.ac.jp
}

Received 22 August 2014; revised 20 September 2014; accepted 15 October 2014

Copyright (C) 2014 by authors and Scientific Research Publishing Inc.

This work is licensed under the Creative Commons Attribution International License (CC BY). http://creativecommons.org/licenses/by/4.0/

(c) (7) Open Access

\section{Abstract}

Objective: To determine outcomes and prognostic factors for early-stage cervical adenocarcinoma/adenosquamous carcinomas (AC/ASC) patients who are treated with radical hysterectomy and adjuvant therapy to optimize their treatment. Methods: We retrospectively reviewed the medical records of 26 patients with International Federation of Gynecologists and Obstetricians stage IB-IIB cervical AC/ASC who were treated with radical hysterectomy and adjuvant therapy. Overall survival (OS) and progression-free survival (PFS) were calculated using the Kaplan-Meier method and compared using the log-rank test. The prognostic significance of various clinical features was determined by using multivariate analysis with the Cox proportional hazards regression model. Results: Univariate analysis revealed that OS was significantly shorter in patients with lymph node metastasis and lymphovascular space invasion. Similarly, PFS was significantly shorter for patients with lymph node metastasis and parametrial invasion. Furthermore, multivariate analysis showed that lymph node metastasis was the only independent predictor for PFS (hazard ratio: $6.47,95 \%$ confidence interval: $1.33-31.44, p=0.021$ ). However, the use of adjuvant chemoradiotherapy did not have any significant effect on either OS or PFS, regardless of lymph node metastasis. Conclusions: Lymph node metastasis is an independent prognostic factor for poor survival in cervical AC/ASC patients treated with radical hysterectomy and adjuvant therapy. In addition, adjuvant chemoradiotherapy does not improve their survival, regardless of lymph node metastasis, which suggests that novel or personalized adjuvant therapeutic strategies with fewer adverse effects than existing strategies are needed.

\footnotetext{
*Corresponding author.
}

How to cite this paper: Yamaguchi, M., et al. (2014) Outcomes and Prognostic Factors for Adenocarcinoma/Adenosquamous Carcinomas Treated with Radical Hysterectomy and Adjuvant Therapy. Open Journal of Obstetrics and Gynecology, 4, 909-915. http://dx.doi.org/10.4236/ojog.2014.414128 


\section{Keywords}

\section{Adjuvant Therapy, Cervical Adenocarcinoma, Cervical Adenosquamous Carcinoma, Lymph Node Metastasis, Prognostic Factors}

\section{Introduction}

Adenocarcinoma/adenosquamous carcinomas (AC/ASC) are relatively uncommon histological subtypes of cervical cancer. Recently, AC/ASC has accounted for approximately $20 \%$ of all cervical cancer cases [1]-[3]. In general, the prognoses of patients with cervical AC/ASC are poorer than those of patients with cervical squamous cell carcinoma (SCC), because AC/ASC is more likely to grow aggressively and metastasize [4] [5]. This may be partly due to the lack of consensus on the optimal treatment for cervical AC/ASC [6]. The first-line treatment for AC/ASC is similar to that for SCC [7] [8]; cervical cancer patients with AC/ASC that are classified as stage IB-IIB by the International Federation of Gynecologists and Obstetricians (FIGO) are often treated with radical hysterectomy [9]. However, there are conflicting reports about whether the prognoses of AC/ASC patients who undergo surgery or radiotherapy are worse than those of SCC patients [5] [10]-[13].

To help resolve this issue, we aim to identify outcomes and prognostic factors in early-stage cervical AC/ ASC patients who are treated with radical hysterectomy and adjuvant therapy. This information may be useful in optimizing the treatment of these patients.

\section{Patients and Methods}

After obtaining approval from the Institutional Review Board of Niigata University Hospital, we retrospectively reviewed the medical records of 26 patients with FIGO stage IB-IIB cervical AC/ASC who were treated with radical hysterectomy and adjuvant therapy between January 2001 and April 2013. Fifteen patients received neoadjuvant chemotherapy with at least one cycle of cisplatin (10 mg/body on days 1 - 10 every four weeks) and 5-fluorouracil (250 mg/body on days 1 - 10 every four weeks) [14]. One patient received a cycle of paclitaxel (175 mg/m $\mathrm{m}^{2}$ on day 1every three weeks) and cisplatin $\left(75 \mathrm{mg} / \mathrm{m}^{2}\right.$ on day 1every three weeks) [15]. The remaining patients did not receive any neoadjuvant therapy. All patients underwent type III Piver-Rutledge radical hysterectomy [16] and systematic pelvic lymphadenectomy.

Approximately four weeks after surgery, all patients received radiotherapy (RT), chemotherapy (CT), or concurrent chemoradiotherapy (CCRT) as adjuvant therapy. RT consisted of external whole pelvic irradiation with 50.4 Gy in 28 fractions. CT (docetaxel: $70 \mathrm{mg} / \mathrm{m}^{2}$ on day 1; carboplatin: area under the curve $=5$ on day 1 ) was administered for at least three cycles at three-week intervals. CCRT consisted of concurrent RT and cisplatin alone (30 - $40 \mathrm{mg} / \mathrm{m}^{2}$ weekly) or cisplatin ( $50 \mathrm{mg} / \mathrm{m}^{2}$ every three weeks) plus paclitaxel ( $50 \mathrm{mg} / \mathrm{m}^{2}$ weekly). The differential indications for these therapies were based on the presence or absence of risk factors for postoperative recurrence, such as lymph node metastasis, parametrial invasion, positive surgical margin, large tumor size ( $\geq 4 \mathrm{~cm}$ ), lymphovascular space invasion (LVSI), and deep stromal invasion ( $\geq 2 / 3$ thickness). For example, among patients without lymph node metastasis, five received CCRT and eight received either RT or CT alone. On the other hand, among patients with lymph node metastasis, four received CCRT and nine received either RT or CT alone.

Survival outcomes were examined using the Kaplan-Meier method and compared using the log-rank test. Multivariate analyses of overall survival (OS) and progression-free survival (PFS) were performed with the Cox proportional hazards regression model to determine the prognostic significance of clinical features. A p-value of less than 0.05 was considered statistically significant.

\section{Results}

Patient characteristics are shown in Table 1. The median age at the start of treatment was 48.0 years (range: 29 69 years). For all patients, the estimated five-year OS rate was $49.5 \%$ and the estimated five-year PFS rate was $36.5 \%$. Disease recurrence occurred in 12 patients (46.2\%) with a median time of 11 months (range: 2 - 57 months). All patients except one had at least one risk factor for postoperative recurrence. However, the patient 
Table 1. Clinicopathological characteristics of the 26 patients with cervical adenocarcinoma/adenosquamous carcinomas in this study.

\begin{tabular}{|c|c|c|}
\hline Clinical stage (FIGO) & Number of patients & Percentage \\
\hline IB1 & 7 & 27 \\
\hline IB2 & 13 & 50 \\
\hline IIA2 & 1 & 4 \\
\hline IIB & 5 & 19 \\
\hline \multicolumn{3}{|l|}{ Age (years) } \\
\hline $20-39$ & 9 & 35 \\
\hline $40-49$ & 4 & 15 \\
\hline $50-59$ & 7 & 27 \\
\hline $60-69$ & 6 & 23 \\
\hline \multicolumn{3}{|l|}{ Histological subtype } \\
\hline Adenocarcinoma & 23 & 88 \\
\hline Adenosquamous carcinoma & 3 & 12 \\
\hline \multicolumn{3}{|l|}{ Adjuvant therapy } \\
\hline Concurrent chemoradiotherapy & 9 & 35 \\
\hline Cisplatin & 5 & \\
\hline Paclitaxel + Cisplatin & 4 & \\
\hline Radiotherapy alone & 3 & 11 \\
\hline Chemotherapy alone & 14 & 54 \\
\hline Docetaxel + Carboplatin & 13 & \\
\hline Paclitaxel + Cisplatin & 1 & \\
\hline
\end{tabular}

who did not have any risk factors still received adjuvant RT because cervical adenocarcinoma has a high risk of recurrence.

As shown in Table 2, lymph node metastasis was a significant prognostic factor for both OS and PFS. In addition, LVSI was a significant prognostic factor for only OS and parametrial invasion was a significant prognostic factor for only PFS. When these prognostic factors were further assessed using the Cox multivariate proportional hazard model, lymph node metastasis was identified as an independent predictor of PFS ( $\mathrm{p}=0.021$, risk ratio $=6.47,95 \%$ confidence interval: 1.33 - 31.43).

The effects of different types of adjuvant therapy in patients with and in those without lymph node metastasis on OS and PFS are shown in Figure 1. In patients with lymph node metastasis, relapses occurred in 10 patients (seven who did not receive CCRT and three who received CCRT). Compared with CT or RT alone, the effects of CCRT on OS and PFS were not significant. In patients without lymph node metastasis, relapses only occurred in two patients who did not receive CCRT. However, compared with CT or RT alone, the effects of CCRT on OS and PFS were not significant.

\section{Discussion}

In this study, we demonstrated that lymph node metastasis is an independent predictor of PFS in patients with cervical AC/ASC who are treated with radical hysterectomy and adjuvant therapy. This result is consistent with several other studies that show that lymph node metastasis in patients with cervical AC/ASC is an independent predictor for survival [9] [17] [18]. However, the type of adjuvant therapy did not make any significant difference on either OS or PFS, regardless of lymph node metastasis. 
Table 2. Multivariate analysis of survival for patients with cervical adenocarcinoma/adenosquamous carcinomas.

\begin{tabular}{|c|c|c|c|c|c|c|c|c|c|c|c|c|}
\hline \multirow[b]{2}{*}{ Covariate } & & \multirow[b]{2}{*}{$n$} & \multicolumn{5}{|c|}{ OS } & \multicolumn{5}{|c|}{ PFS } \\
\hline & & & $\begin{array}{c}\text { Estimated } \\
\text { 5-year } \\
\text { survival } \\
(\%)\end{array}$ & $\begin{array}{c}\text { Univariate } \\
\text { p-value }\end{array}$ & $\mathrm{RR}$ & $\begin{array}{c}95 \% \\
\text { CI }\end{array}$ & $\begin{array}{c}\text { Multivariate } \\
\text { p-value }\end{array}$ & $\begin{array}{l}\text { Estimated } \\
\text { 5-year } \\
\text { survival } \\
(\%)\end{array}$ & $\begin{array}{l}\text { Univariate } \\
\text { p-value }\end{array}$ & $\mathrm{RR}$ & $\begin{array}{c}95 \% \\
\text { CI }\end{array}$ & $\begin{array}{l}\text { Multivariate } \\
\text { p-value }\end{array}$ \\
\hline \multirow{2}{*}{ Age } & $<50$ years & 13 & 61.4 & 0.904 & & & & 42.1 & 0.982 & & & \\
\hline & $\geq 50$ years & 13 & 40.0 & & & & & 34.6 & & & & \\
\hline \multirow{2}{*}{ Stage } & IB & 20 & 53.8 & 0.188 & & & & 35.5 & 0.597 & & & \\
\hline & IIA+IIB & 6 & 40.0 & & & & & 40.0 & & & & \\
\hline \multirow{2}{*}{ NAC } & Received & 15 & 51.3 & 0.510 & & & & 31.4 & 0.717 & & & \\
\hline & Not received & 11 & $(60.0)^{*}$ & & & & & $(72.7)^{*}$ & & & & \\
\hline \multirow{3}{*}{$\begin{array}{l}\text { Adjuvant } \\
\text { therapy }\end{array}$} & $\begin{array}{c}\text { Concurrent } \\
\text { chemoradiotherapy }\end{array}$ & 9 & $(57.1)^{*}$ & 0.543 & & & & $(63.5)^{*}$ & 0.424 & & & \\
\hline & Radiotherapy alone & 3 & 100.0 & & & & & 100.0 & & & & \\
\hline & Chemotherapy alone & 14 & 46.9 & & & & & 25.6 & & & & \\
\hline \multirow{2}{*}{$\begin{array}{l}\text { Lymph node } \\
\text { metastasis }\end{array}$} & Negative & 13 & 80.0 & 0.023 & 7.21 & $\begin{array}{l}0.89- \\
58.46\end{array}$ & 0.064 & 65.6 & 0.0027 & 6.47 & $\begin{array}{l}1.33- \\
31.43\end{array}$ & 0.021 \\
\hline & Positive & 13 & 30.0 & & & & & 17.1 & & & & \\
\hline \multirow{2}{*}{$\begin{array}{l}\text { Parametrial } \\
\text { invasion }\end{array}$} & Negative & 19 & 54.1 & 0.158 & & & & 60.4 & 0.0158 & 2.68 & $\begin{array}{l}0.83- \\
8.66\end{array}$ & 0.099 \\
\hline & Positive & 7 & 33.3 & & & & & 0 & & & & \\
\hline \multirow{2}{*}{$\begin{array}{l}\text { Surgical } \\
\text { margin }\end{array}$} & Negative & 25 & 52.2 & 0.207 & & & & 38.4 & 0.097 & & & \\
\hline & Positive & 1 & 0 & & & & & 0 & & & & \\
\hline \multirow{2}{*}{$\begin{array}{l}\text { Maximum } \\
\text { tumor } \\
\text { diameter }\end{array}$} & $<4 \mathrm{~cm}$ & 9 & 60.0 & 0.259 & & & & 44.4 & 0.291 & & & \\
\hline & $\geq 4 \mathrm{~cm}$ & 17 & 46.2 & & & & & 30.9 & & & & \\
\hline \multirow[t]{2}{*}{ LVSI } & Negative & 13 & 75.0 & 0.035 & 4.41 & $\begin{array}{l}0.89- \\
21.98\end{array}$ & 0.070 & 37.7 & 0.126 & & & \\
\hline & Positive & 13 & 25.6 & & & & & 36.1 & & & & \\
\hline \multirow{2}{*}{$\begin{array}{c}\text { Deep } \\
\text { stromal } \\
\text { invasion }\end{array}$} & Negative & 8 & 83.3 & 0.371 & & & & 65.6 & 0.256 & & & \\
\hline & Positive & 18 & 41.9 & & & & & 26.0 & & & & \\
\hline
\end{tabular}

Abbreviations: OS: overall survival, PFS: progression-free survival, LVSI: lymphovascular space invasion, RR: risk ratio, CI: confidence interval. ${ }^{*}$ Parenthetical values indicate that all cases were assessed before year 5.

Since there is no agreement about the optimal treatment for cervical AC/ASC, patients with AC/ASC tend to be treated similarly to those with SCC, namely, radical hysterectomy followed by adjuvant therapy [13]. Rotman et al. [19] suggested that postoperative adjuvant therapy, particularly RT, may be more beneficial for AC/ASC than for SCC. However, there are conflicting reports in the literature about the effect of CCRT on cervical AC/ASC. Some studies have shown that CCRT is beneficial for cervical AC/ASC [20]-[23], while other studies have reported that CCRT does not improve the survival of patients with risk factors, such as lymph node metastasis [22] [23]. In this study, we showed that CCRT did not improve the survival of patients compared with either RT or CT alone, regardless of lymph node metastasis (Figure 1). However, our small sample sizelimits the statistical power of this study. As a result, a larger study is needed to confirm the generality of this conclusion.

These results suggest that other adjuvant therapeutic strategies may be needed to improve the survival of patients with cervical AC/ASC. For example, Park et al. [24] suggested that adjuvant therapy should be tailored 


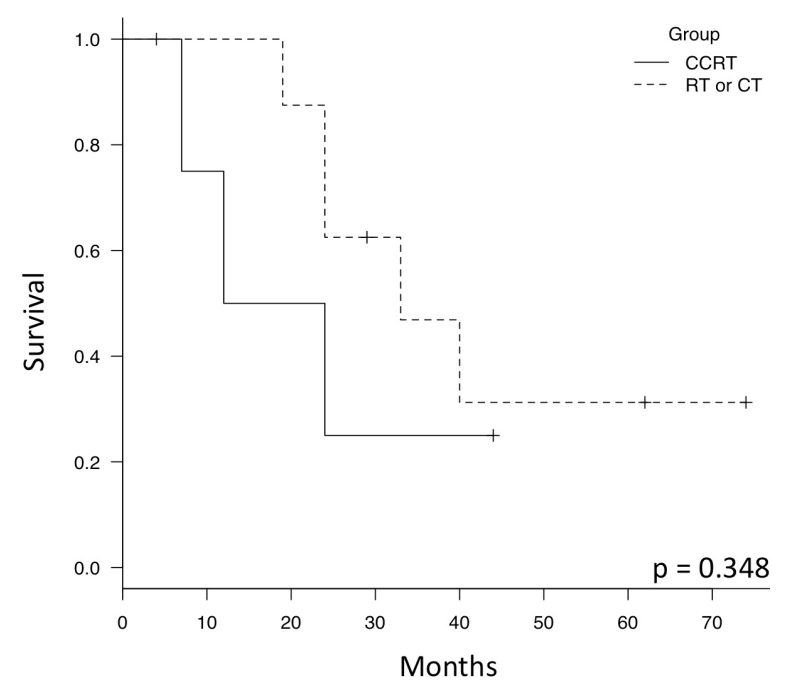

(a)

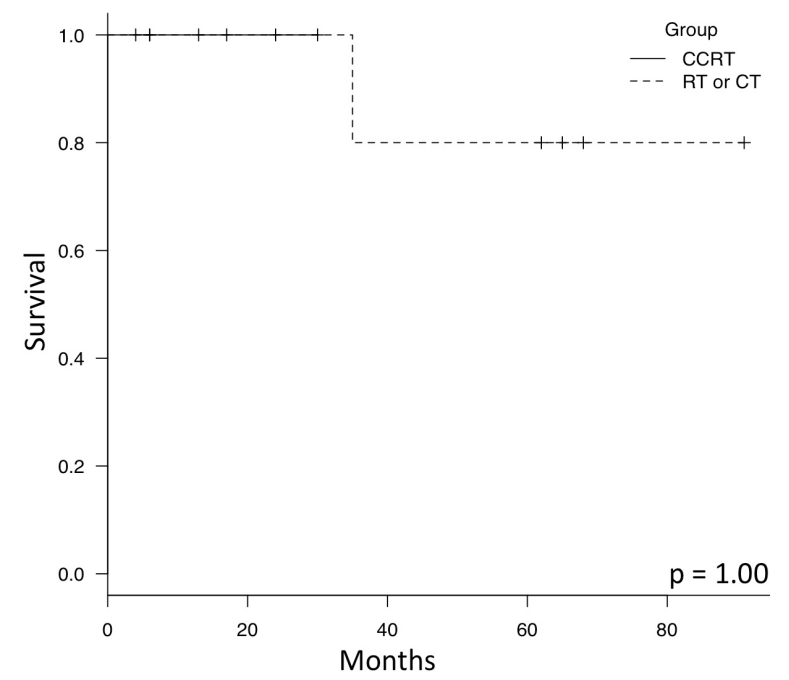

(c)

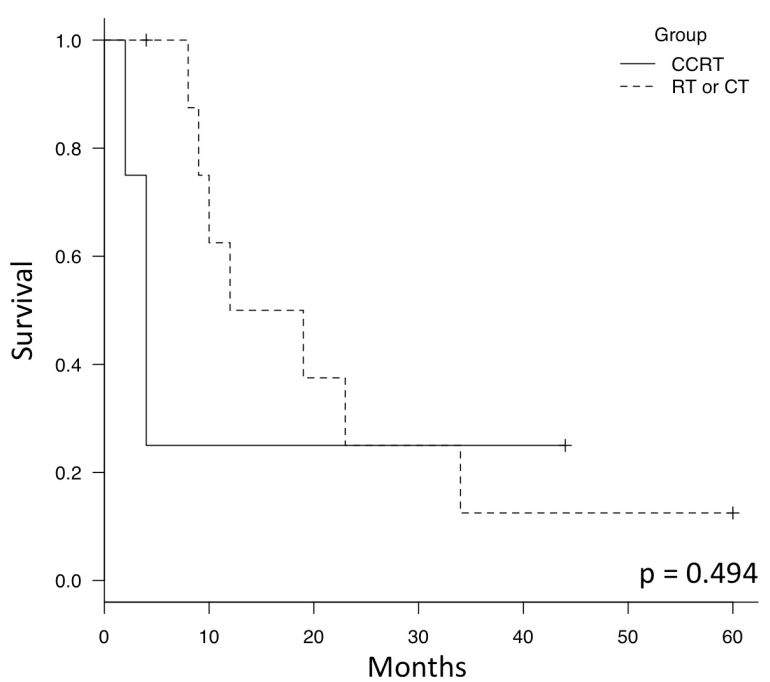

(b)

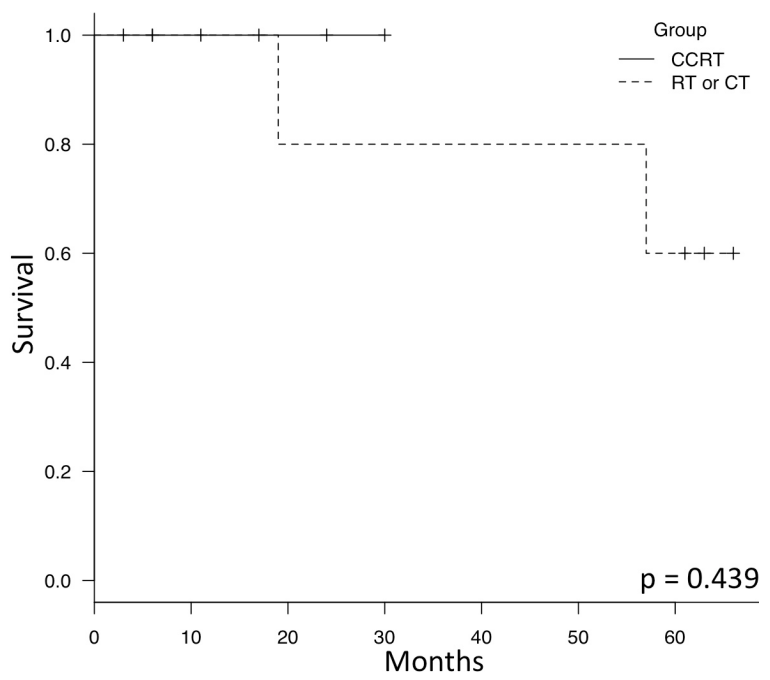

(d)

Figure 1. Kaplan-Meier analysis comparing the effects of adjuvant radiotherapy, chemotherapy, or concurrent chemoradiotherapy in patients with cervical adenocarcinoma/adenosquamous carcinomas. (a) Overall survival of patients with lymph node metastasis; (b) Progression-free survival of patients with lymph node metastasis; (c) Overall survival of patients without lymph node metastasis; (d) Progression-free survival of patients without lymph node metastasis.

according to postoperative risk factors in patients with early stage adenocarcinoma. Since CCRT has many adverse effects [15] [20], personalizing adjuvant therapydepending on the presence or absence of lymph node metastasis to reduce adverse effectsmay be worth considering.

\section{Conclusion}

In conclusion, we found that lymph node metastasis was an independent prognostic factor for poor survival in cervical AC/ASC patients treated with radical hysterectomy and adjuvant therapy. In this study, CCRT does not improve patient survival, regardless of lymph node metastasis, which suggests that novel or personalized adjuvant therapeutic strategies with fewer adverse effects than existing strategies are needed.

\section{References}

[1] Sherman, M.E., Wang, S.S., Carreon, J. and Devesa, S.S. (2005) Mortality Trends for Cervical Squamous and Adenocarcinoma in the United States. Relation to Incidence and Survival. Cancer, 103, 1258-1264. 
http://dx.doi.org/10.1002/cncr.20877

[2] Bray, F., Carstensen, B., Møller, H., Zappa, M., Zakelj, M.P., Lawrence, G., Hakama, M. and Weiderpass, E. (2005) Incidence Trends of Adenocarcinoma of the Cervix in 13 European Countries. Cancer Epidemiology, Biomarkers \& Prevention, 14, 2191-2199. http://dx.doi.org/10.1158/1055-9965.EPI-05-0231

[3] Kurman, R.J., Ellenson, L.H. and Ronnett, B.M. (2011) Blaustein’s Pathology of the Female Tract. 6th Edition, Springer, New York, 273-274. http://dx.doi.org/10.1007/978-1-4419-0489-8

[4] Look, K.Y., Brunetto, V.L., Clarke-Pearson, D.L., Averette, H.E., Major, F.J., Alvarez, R.D., Homesley, H.D. and Zaino, R.J. (1996) An Analysis of Cell Type in Patients with Surgically Staged Stage IB Carcinoma of the Cervix: A Gynecologic Oncology Group Study. Gynecologic Oncology, 63, 304-311. http://dx.doi.org/10.1006/gyno.1996.0327

[5] Eifel, P.J., Burke, T.W., Morris, M. and Smith, T.L. (1995) Adenocarcinoma as an Independent Risk Factor for Disease Recurrence in Patients with Stage IB Cervical Carcinoma. Gynecologic Oncology, 59, 38-44. http://dx.doi.org/10.1006/gyno.1995.1265

[6] ACOG Practice Bulletin No. 35 (2002) Diagnosis and Treatment of Cervical Carcinomas. Obstetrics \&Gynecology, 99, 855-867.

[7] (2013) NCCN Clinical Practice Guidelines in Oncology Cervical Cancer Version 3. http://www.nccn.org/professionals/physician_gls/f_guidelines.asp

[8] (2013) National Cancer Institute Cervical Cancer Treatment $\left(\mathrm{PDQ}^{\circledR}\right)$ Health Professional Version. http://www.cancer.gov/cancertopics/pdq/treatment/cervical/HealthProfessional

[9] Kato, T., Watari, H., Takeda, M., Hosaka, M., Mitamura, T., Kobayashi, N., Sudo, S., Kaneuchi, M., Kudo, M. and Sakuragi, N. (2013) Multivariate Prognostic Analysis of Adenocarcinoma of the Uterine Cervix Treated with Radical Hysterectomy and Systematic Lymphadenectomy. Journal of Gynecologic Oncology, 24, 222-228. http://dx.doi.org/10.3802/jgo.2013.24.3.222

[10] Lai, C.H., Hsueh, S., Hong, J.H., Chang, T.C., Tseng, C.J., Chou, H.H., Huang, K.G. and Lin, J.D. (1999) Are Adenocarcinomas and Adenosquamous Carcinomas Different from Squamous Carcinomas in Stage IB and II Cervical Cancer Patients Undergoing Primary Radical Surgery? International Journal of Gynecological Cancer, 9, 28-36. http://dx.doi.org/10.1046/j.1525-1438.1999.09895.x

[11] Huang, Y.T., Wang, C.C., Tsai, C.S., Lai, C.H., Chang, T.C., Chou, H.H., Hsueh, S., Chen, C.K., Lee, S.P. and Hong, J.H. (2011) Long-Term Outcome and Prognostic Factors for Adenocarcinoma/Adenosquamous Carcinoma of Cervix after Definitive Radiotherapy. International Journal of Radiation Oncology, Biology, Physics, 80, 429-436. http://dx.doi.org/10.1016/j.ijrobp.2010.02.009

[12] Ayhan, A., Al, R.A., Baykal, C., Demirtas, E., Yüce, K. and Ayhan, A. (2004) A Comparison of Prognoses of FIGO Stage IB Adenocarcinoma and Squamous Cell Carcinoma. International Journal of Gynecological Cancer, 14, 279285. http://dx.doi.org/10.1111/j.1048-891X.2004.014211.x

[13] Kasamatsu, T., Onda, T., Sawada, M., Kato, T., Ikeda, S., Sasajima, Y. and Tsuda, H. (2009) Radical Hysterectomy for FIGO Stage I-IIB Adenocarcinoma of the Uterine Cervix. British Journal of Cancer, 100, 1400-1405. http://dx.doi.org/10.1038/sj.bjc.6605048

[14] Aoki, Y., Sato, T., Watanabe, M., Sasaki, M., Tsuneki, I. and Tanaka, K. (2001) Neoadjuvant Chemotherapy Using Low-Dose Consecutive Intraarterial Infusions of Cisplatin Combined with 5-Fluorouracil for Locally Advanced Cervical Adenocarcinoma. Gynecologic Oncology, 81, 496-499. http://dx.doi.org/10.1006/gyno.2001.6195

[15] Tang, J., Tang, Y., Yang, J. and Huang, S. (2012) Chemoradiation and Adjuvant Chemotherapy in Advanced Cervical Adenocarcinoma. Gynecologic Oncology, 125, 297-302. http://dx.doi.org/10.1016/j.ygyno.2012.01.033

[16] Piver, M.S., Rutledge, F. and Smith, J.P. (1974) Five Classes of Extended Hysterectomy for Women with Cervical Cancer. Obstetrics \&Gynecology, 44, 265-272.

[17] Baalbergen, A., Ewing-Graham, P.C., Hop, W.C., Struijk, P. and Helmerhorst, T.J. (2004) Prognostic Factors in Adenocarcinoma of the Uterine Cervix. Gynecologic Oncology, 92, 262-267. http://dx.doi.org/10.1016/j.ygyno.2003.09.001

[18] Shingleton, H.M., Bell, M.C., Fremgen, A., Chmiel, J.S., Russell, A.H., Jones, W.B., Winchester, D.P. and Clive, R.E. (1995) Is There Really a Difference in Survival of Women with Squamous Cell Carcinoma, Adenocarcinoma, and Adenosquamous Cell Carcinoma of the Cervix? Cancer, 76, 1948-1955.

[19] Rotman, M., Sedlis, A., Piedmonte, M.R., Bundy, B., Lentz, S.S., Muderspach, L.I. and Zaino, R.J. (2006) A Phase III Randomized Trial of Postoperative Pelvic Irradiation in Stage IB Cervical Carcinoma with Poor Prognostic Features: Follow-Up of a Gynecologic Oncology Group Study. International Journal of Radiation Oncology, Biology, Physics, 65, 169-176. http://dx.doi.org/10.1016/j.ijrobp.2005.10.019

[20] Peters 3rd, W.A., Liu, P.Y., Barrett 2nd, R.J., Stock, R.J., Monk, B.J., Berek, J.S., Souhami, L., Grigsby, P., Gordon Jr., W. and Alberts, D.S. (2000) Concurrent Chemotherapy and Pelvic Radiation Therapy Compared with Pelvic Radiation 
Therapy Alone as Adjuvant Therapy after Radical Surgery in High-Risk Early-Stage Cancer of the Cervix. Journal of Clinical Oncology, 18, 1606-1613.

[21] Chen, Y.L., Ho, C.M., Chen, C.A., Chiang, Y.C., Huang, C.Y., Hsieh, C.Y. and Cheng, W.F. (2011) Impact of Various Treatment Modalities on the Outcome of Stage IB1-IIA Cervical Adenocarcinoma. International Journal of Gynaecology \& Obstetrics, 112, 135-139. http://dx.doi.org/10.1016/j.ijgo.2010.08.016

[22] Huang, Y.T., Wang, C.C., Tsai, C.S., Lai, C.H., Chang, T.C., Chou, H.H., Lee, S.P. and Hong, J.H. (2012) Clinical Behaviors and Outcomes for Adenocarcinoma or Adenosquamous Carcinoma of Cervix Treated by Radical Hysterectomy and Adjuvant Radiotherapy or Chemoradiotherapy. International Journal of Radiation Oncology, Biology, Physics, 84, 420-427. http://dx.doi.org/10.1016/j.ijrobp.2011.12.013

[23] Mabuchi, S., Okazawa, M., Matsuo, K., Kawano, M., Suzuki, O., Miyatake, T., Enomoto, T., Kamiura, S., Ogawa, K. and Kimura, T. (2012) Impact of Histological Subtype on Survival of Patients with Surgically-Treated Stage IA2-IIB Cervical Cancer: Adenocarcinoma versus Squamous Cell Carcinoma. Gynecologic Oncology, 127, 114-120. http://dx.doi.org/10.1016/j.ygyno.2012.06.021

[24] Park, J.Y., Kim, D.Y., Kim, J.H., Kim, Y.M., Kim, Y.T. and Nam, J.H. (2010) Outcomes after Radical Hysterectomy in Patients with Early-Stage Adenocarcinoma of Uterine Cervix. British Journal of Cancer, 102, 1692-1698. http://dx.doi.org/10.1038/sj.bjc.6605705 
Scientific Research Publishing (SCIRP) is one of the largest Open Access journal publishers. It is currently publishing more than 200 open access, online, peer-reviewed journals covering a wide range of academic disciplines. SCIRP serves the worldwide academic communities and contributes to the progress and application of science with its publication.

Other selected journals from SCIRP are listed as below. Submit your manuscript to us via either submit@scirp.org or Online Submission Portal.
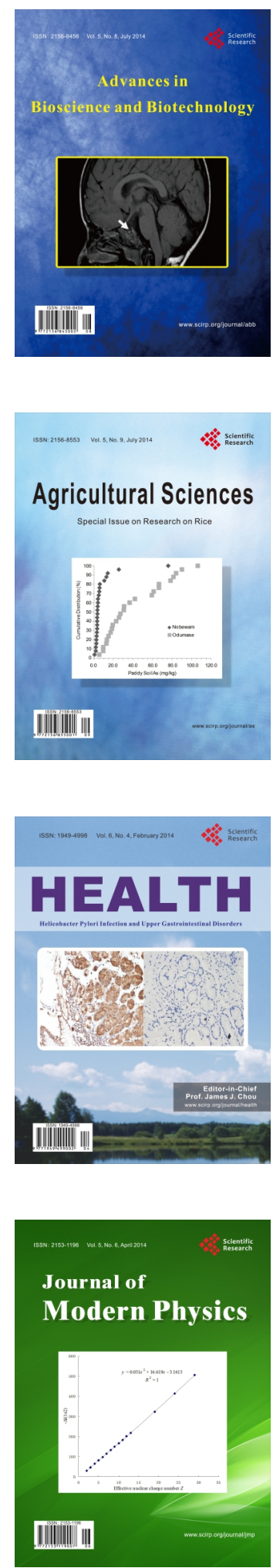
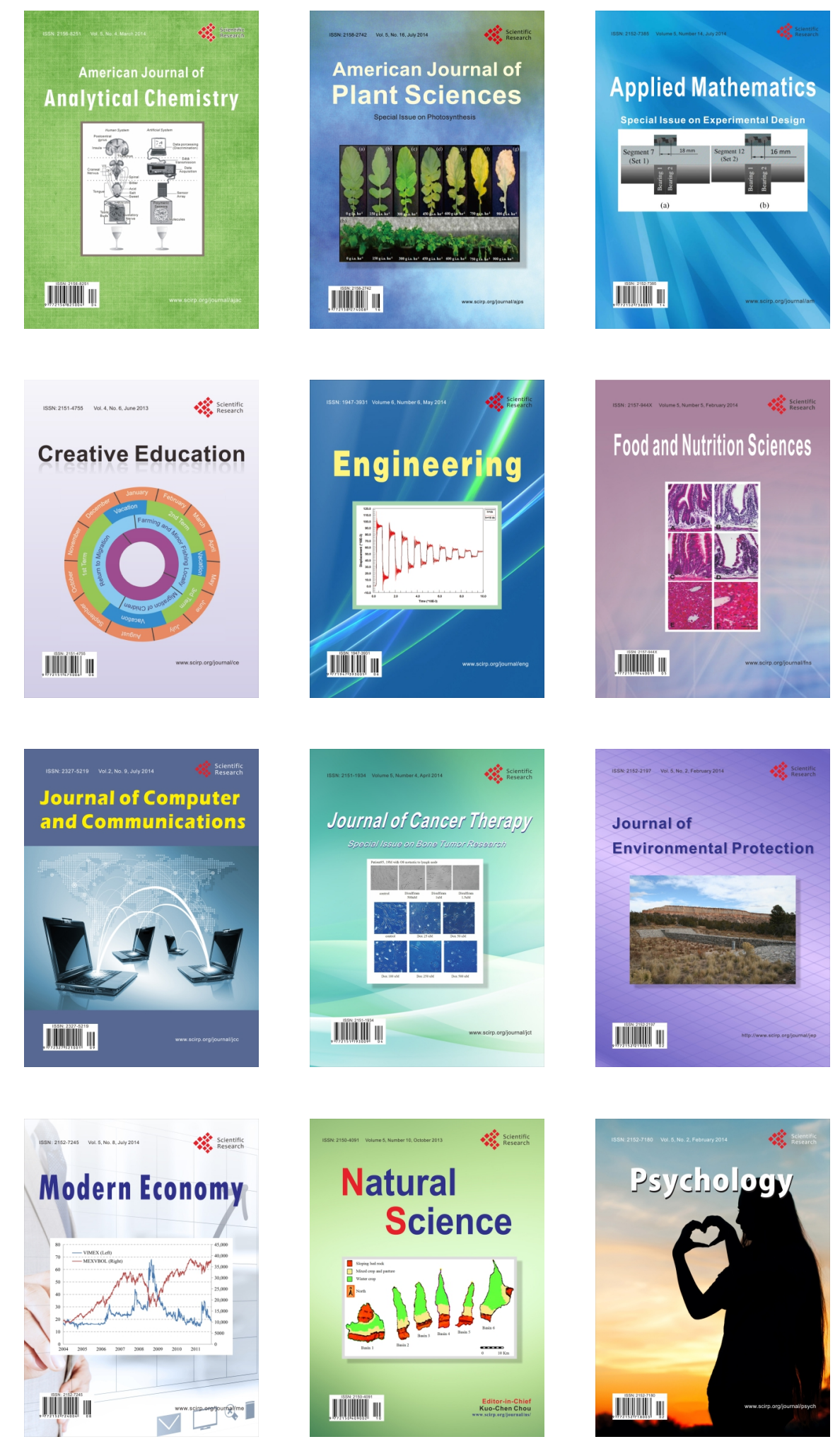